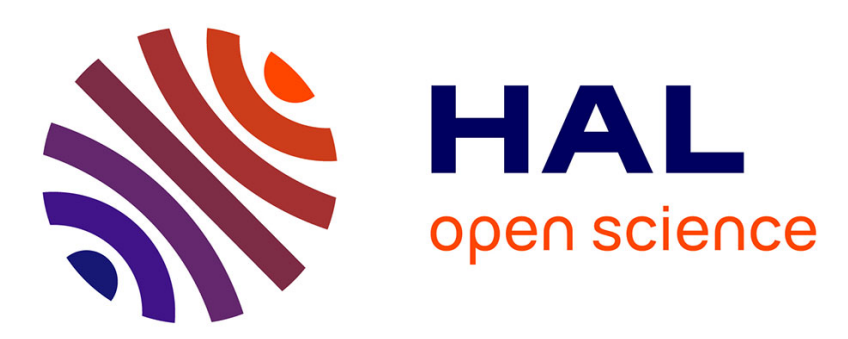

\title{
Two air path observers for turbocharged SI engines with VCT
}

\author{
Guillaume Colin, Gérard Bloch, Yann Chamaillard, Floriane Anstett
}

\section{To cite this version:}

Guillaume Colin, Gérard Bloch, Yann Chamaillard, Floriane Anstett. Two air path observers for turbocharged SI engines with VCT. Control Engineering Practice, 2009, 17 (5), pp.571-578. 10.1016/j.conengprac.2008.10.001 . hal-00327575

\section{HAL Id: hal-00327575 \\ https://hal.science/hal-00327575}

Submitted on 8 Oct 2008

HAL is a multi-disciplinary open access archive for the deposit and dissemination of scientific research documents, whether they are published or not. The documents may come from teaching and research institutions in France or abroad, or from public or private research centers.
L'archive ouverte pluridisciplinaire HAL, est destinée au dépôt et à la diffusion de documents scientifiques de niveau recherche, publiés ou non, émanant des établissements d'enseignement et de recherche français ou étrangers, des laboratoires publics ou privés. 


\title{
Two air path observers for turbocharged SI engines with $\mathrm{VCT}$
}

\author{
Guillaume Colin $^{\mathrm{a}, *}$, Gérard Bloch ${ }^{\mathrm{b}}$, Yann Chamaillard ${ }^{\mathrm{a}}$, Floriane Anstett ${ }^{\mathrm{b}}$ \\ ${ }^{a}$ Institut Pluridisciplinaire de Recherche en Ingénierie des Systèmes, Mécanique, \\ Energétique (PRISME), University of Orléans, \\ 8, rue Léonard de Vinci, 45072 Orléans, France \\ ${ }^{b}$ Centre de Recherche en Automatique de Nancy (CRAN), Nancy-University, CNRS, \\ CRAN-ESSTIN, rue Jean Lamour, 54519 Vandoeuvre Cedex, France
}

\begin{abstract}
Nowadays, downsizing is a major way to reduce fuel consumption and pollutant emissions of Spark Ignition (SI) engines. In downsized engines, new air path management systems such as turbocharging or Variable Camshaft Timing (VCT) are including, and an efficient control of the air actuators is required for engine torque control. Two non-linear estimators are proposed to estimate non-measured variables of the air path. The first one is an incylinder air mass observer that combines feedforward neural static models and a Linear Parameter Varying (LPV) polytopic observer. The second one is a neural estimator of the burned gas and the air scavenged masses. Test bench results on a turbocharged SI engine with VCT show the real time applicability and good performance of the proposed estimators. Finally, a strategy for developing the engine supervisor is presented.
\end{abstract}

Key words: engine control, SI engine, non-linear observer, neural networks, LPV system.

\footnotetext{
${ }^{*}$ Corresponding author.

Email addresses: guillaume.colin@univ-orleans.fr (Guillaume Colin), gerard.bloch@esstin.uhp-nancy.fr (Gérard Bloch), yann.chamaillard@univ-orleans.fr (Yann Chamaillard), floriane.collin@uha.fr (Floriane Anstett)
} 


\section{Introduction}

\subsection{Context}

Increasingly stringent standards are being imposed to reduce fuel consumption and pollutant emissions for Spark Ignition (SI) engines. Modern automobile engines must therefore satisfy the challenging, and often conflicting, goals of minimizing pollutant emissions and fuel consumption while satisfying driving performance over a wide range of operating conditions.

To achieve these goals, downsizing appears as a major way for reducing fuel consumption while maintaining the advantage of low emission capability of three-way catalytic systems and combining several well known technologies (Lecointe and Monnier, 2003). Downsizing is the use of a smaller capacity engine operating at higher specific engine loads, i.e. at better efficiency points. In order to feed the engine, turbocharging seems to be the best solution. Unfortunately, the turbocharger inertia involves long torque transient responses (Lecointe and Monnier, 2003; Frei et al., 2006). This problem can be partially solved by combining turbocharging and Variable Camshaft Timing (VCT) which allows air scavenging from the intake to the exhaust. Moreover, VCT decreases pollutants emission, especially nitrogen oxides $\left(N O_{x}\right)$.

\subsection{System description}

The air intake of a turbocharged SI Engine with VCT, represented in Fig. 1 , can be described as follows. The compressor (pressure $p_{\text {int }}$ ) produces a flow from the ambient air (pressure $p_{a m b}$ and temperature $T_{a m b}$ ). This air flow $Q_{t h}$ is adjusted by the intake throttle (section $S_{t h}$ ) and enters the intake manifold (pressure $p_{\text {man }}$ and temperature $T_{\text {man }}$ ). The flow entering the cylinders $Q_{c y l}$ passes through the intake valves, whose timing is controlled by the intake Variable Camshaft Timing $V C T_{\text {in }}$ actuator. After combustion, the gases are expelled into the exhaust manifold through the exhaust valve, controlled by the exhaust Variable Camshaft Timing $V C T_{\text {exh }}$ actuator. The exhaust flow is split in two parts: the turbine and wastegate flows. The turbine flow powers up the turbine and drives the compressor through a shaft. Thus, the supercharged pressure $p_{\text {int }}$ is adjusted by the turbine flow which is controlled by the wastegate $W G$.

The effects of VCT are twofold. Firstly, acting on cam timing can inhibit the production of nitrogen oxides $\left(N O_{x}\right)$ since combustion products which would otherwise be expelled during the exhaust stroke are retained in the cylinder during the subsequent intake stroke. This dilution of the mixture in 


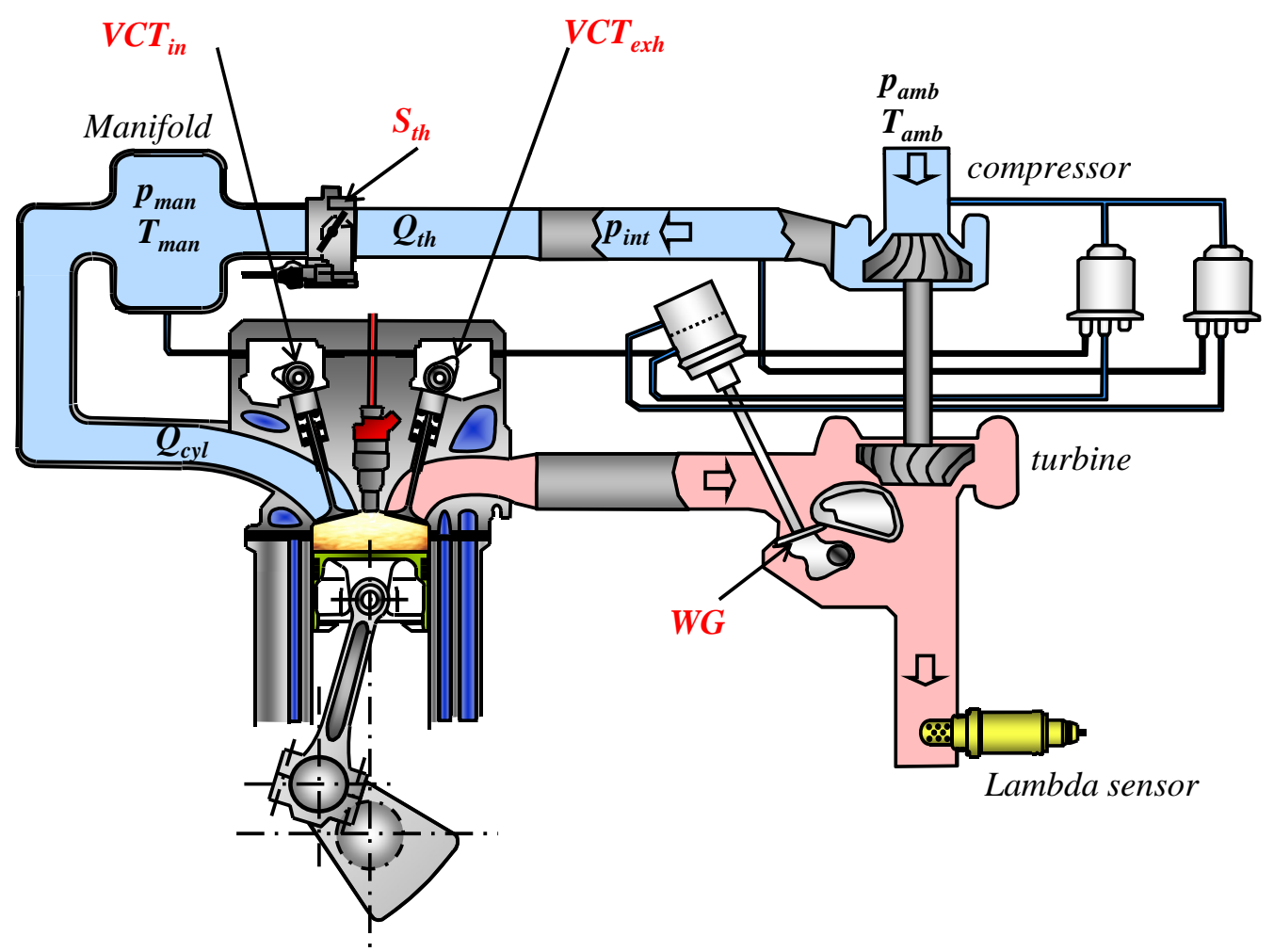

Figure 1: Airpath of a Turbocharged SI Engine with VCT

the cylinder reduces the combustion temperature and limits $N O_{x}$ formation. It is therefore important to control the back-flow of burned gases in the cylinder. Secondly, with camshaft timing, air scavenging can occur, that is air passing directly from the intake to the exhaust through the cylinder. For this to happen, the intake manifold pressure must be greater than the exhaust pressure when the exhaust and intake valves are opened together. Even if air scavenging impacts the air fuel ratio, it is advantageous because it improves the engine torque dynamic behavior, i.e. decreases the settling times. The flow which passes through the turbine is increased and the corresponding energy is transmitted to the compressor. Therefore, in transient, it is very important to control this scavenging.

\subsection{Control and observation structure}

For an SI engine, the torque is directly linked to the air mass trapped in the cylinder $m_{\text {air }}$ for a given engine speed $N_{e}$. For this reason, an efficient 
control of this air mass is required to obtain the desired torque. As the engine must pollute as little as possible, it is also necessary to control the recirculated gas mass in the cylinder $R G M$, which renders both air scavenging and burned gas back-flow and influences pollutant emissions and combustion stability.

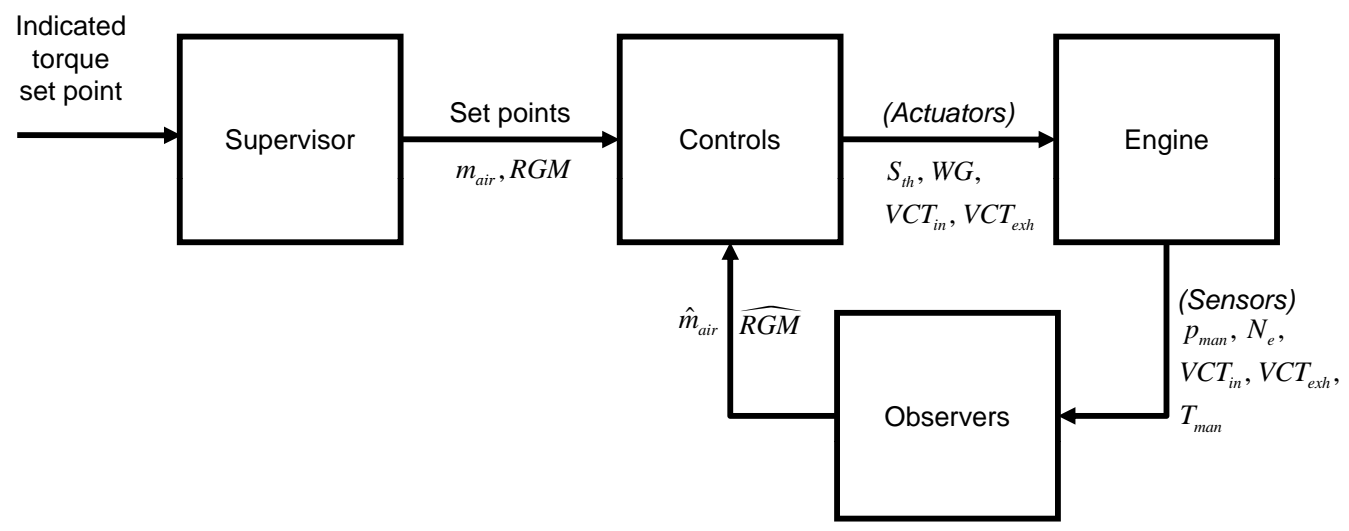

Figure 2: General Control Structure

The work presented here is based on the control structure of the airpath described in Fig. 2. From set points given by a supervisor, this structure makes it possible to control the two air variables $m_{\text {air }}$ and $R G M$ and manipulates the four air actuators, the throttle section $S_{t h}$, the wastegate $W G$ and the intake $V C T_{i n}$ and exhaust $V C T_{\text {exh }}$ twin independent Variable Camshaft Timing actuators. The control algorithms are detailed in (Colin et al., 2007) and combine separate, but coordinated, modules based on different control strategies: Internal Model Control (IMC), Model Predictive Control (MPC), and optimal control.

This paper details the air mass observation part, which is used both for control and determination of optimal set points, and focuses on two non-linear estimators of the air variables: recirculated gas mass $R G M$ (section 2) and in-cylinder air mass $m_{\text {air }}$ (section 3 ). Because these variables are not directly measured, data provided by a complex but accurate high frequency engine simulator (Le Berr et al., 2006) are used to build the corresponding models. The recirculated gas mass $R G M$ estimator is a neural model entirely obtained from the simulated data. The in-cylinder air mass $m_{\text {air }}$ estimator combines feedforward neural static models and a polytopic observer built from the Linear Parameter Varying model of the intake manifold. In the 
last part (section 4), a static test on an engine test bench demonstrates the possible improvement of the engine supervisor. Indeed, by using the observer based control structure, optimal set points in terms of fuel consumption and pollutant emissions can be determined.

The simulated data used to build the models are divided in two sets. The first one is used to estimate the model parameters and is called training data in the sequel. These data are representative of all engine operating points (engine speed, manifold pressure and variable cam timing). The second one, called validation data, is used to determine the optimal internal structure of the models, but also to evaluate their performances when no additional information is available. Finally, test data are also available for the in-cylinder air mass, obtained from the measured air flow through the throttle $Q_{t h}$. However, these rather sparse test bench data are not fully representative (do not contain all the engine operating points in terms of variable cam timing) and are valid only in steady state. They are only used, therefore, to evaluate the final performances of the observers in which the models are included. The test engine is a 1.8 liter turbocharged 4 cylinder engine with Variable Camshaft Timing.

\section{Recirculated Gas Mass model}

Because scavenging and burned gas back-flow correspond to associated flow phenomena, only one variable, the Recirculated Gas Mass $(R G M)$, is defined:

$$
R G M= \begin{cases}m_{b g} & \text { if } m_{b g}>m_{s c} \\ -m_{s c} & \text { else, }\end{cases}
$$

where $m_{b g}$ is the in-cylinder burned gas mass and $m_{s c}$ is the scavenged air mass (positive value). As $R G M$ represents only the most important phenomenon (air scavenging or burned gases), a tiny discontinuity between burned gas back flow $m_{b g}$ and air scavenging $m_{s c}$ can appear. Note that, when there is scavenging from the intake to the exhaust, the burned gases are insignificant. Fig. 3 shows the simulated behavior of the Recirculated Gas Mass RGM w.r.t. the VCT actuators for an operating point, i.e. at a fixed engine speed $\left(N_{e}=2000 \mathrm{rpm}\right)$ and a fixed manifold pressure $\left(p_{\operatorname{man}}=140\right.$ $\mathrm{kPa})$.

Studying this variable is complex because it cannot be measured on-line. Consequently, a static model was built from data provided by the engine 


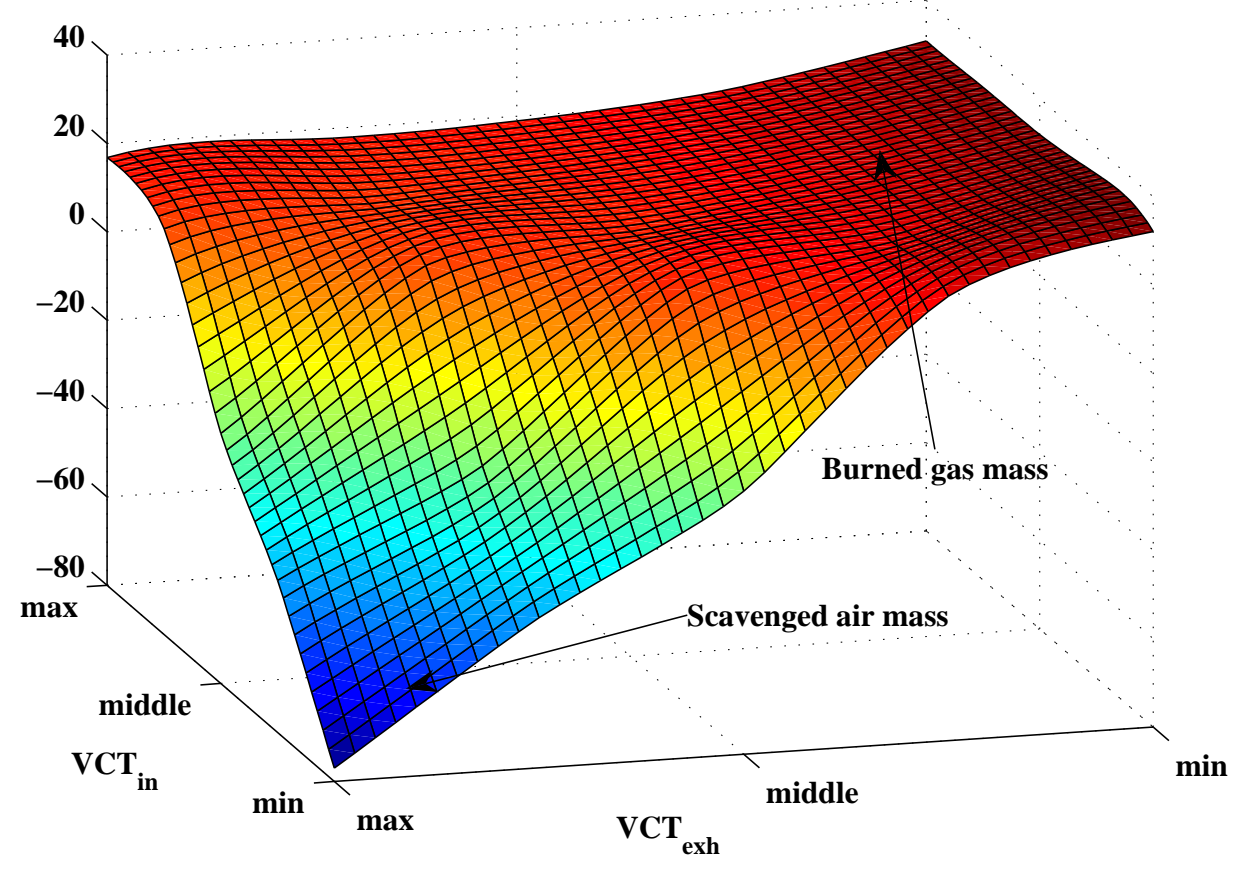

Figure 3: Recirculated Gas Mass (mg) at constant engine speed and manifold pressure

simulator. As a parsimonious and flexible universal approximator, the perceptron with one hidden layer and with a linear output unit was chosen for this model. For a single output, the output $f_{n n}$ of such a model is given by:

$$
f_{n n}=\sum_{k=1}^{n} w_{k}^{2} g\left(\sum_{j=1}^{p} w_{k j}^{1} \varphi_{j}+b_{k}^{1}\right)+b^{2},
$$

where the $\varphi_{j}$ are the $p$ regressors, the $w_{k j}^{1}, b_{k}^{1}$ are the parameters of the $n$ hidden neurons, the activation function $g$ is the hyperbolic tangent, and the $w_{k}^{2}, b^{2}$ are the weights and bias of the output neuron.

The choice of regressors is based on physical considerations and the estimated Recirculated Gas Mass $\widehat{R G M}$ is given by:

$$
\widehat{R G M}=f_{n n}\left(p_{m a n}, N_{e}, V C T_{i n}, V C T_{e x h}\right),
$$

where $p_{\text {man }}$ is the intake manifold pressure, $N_{e}$ the engine speed, $V C T_{\text {in }}$ the intake camshaft timing, and $V C T_{e x h}$ the exhaust camshaft timing. 

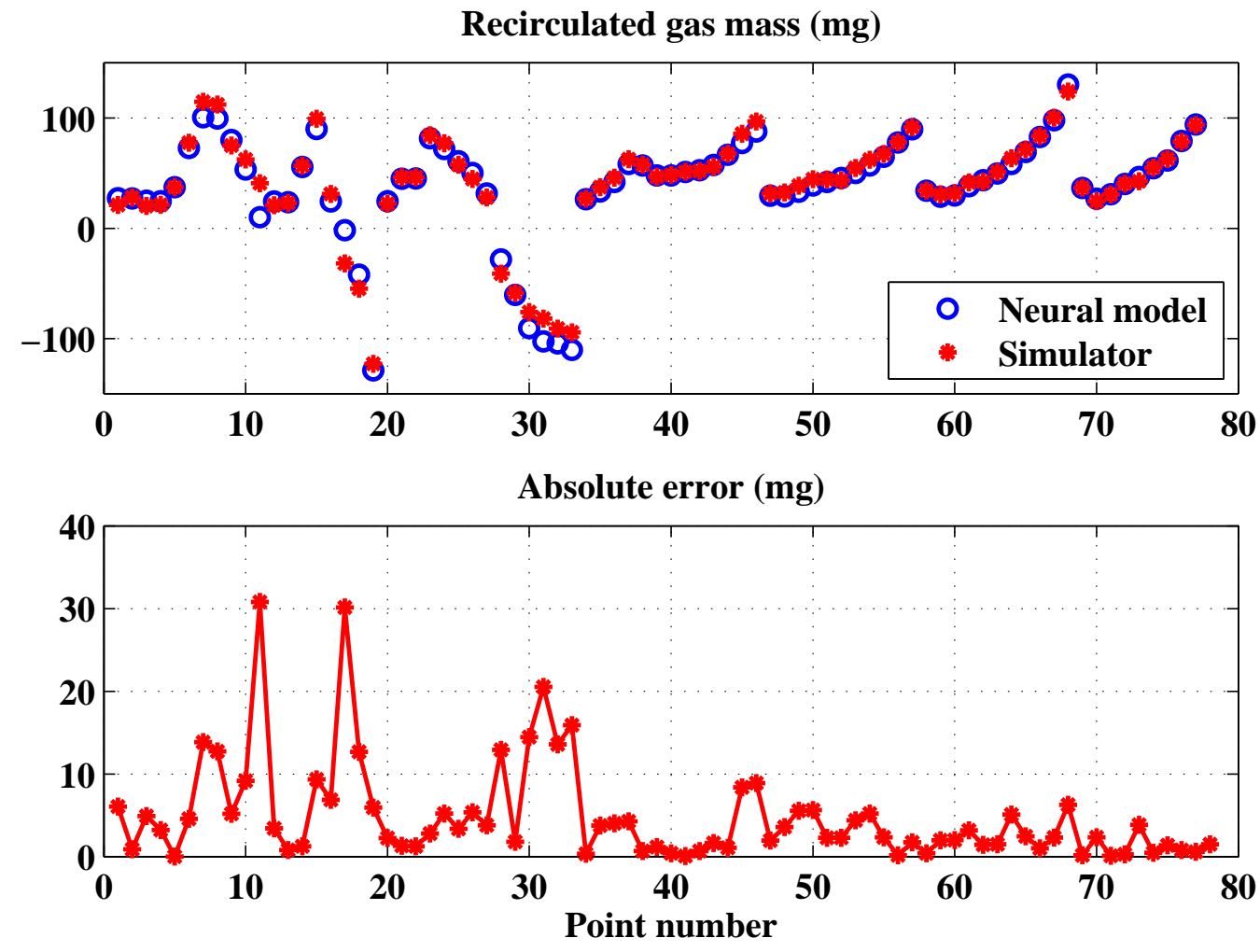

Figure 4: RGM model (up, in mg) and its absolute errors (down, in mg) on validation data

Training was performed by minimizing the mean squared error, with the Levenberg-Marquardt algorithm. In order to determine the optimal internal structure of the model, two criteria, the Bayesian Information Criterion (BIC) and the Final Prediction Error (FPE) criterion, are examined from the validation data, when varying the number $n$ of hidden neurons (Nelles, 2000). The optimal number of hidden neurons corresponds to the minimum of the criteria and is found to be equal to 12. Fig. 4 shows the recirculated gas mass estimation and its absolute error on the validation data. The neural model gives satisfactory results with a Root Mean Squared Error (RMSE) of about $4.8 \mathrm{mg}$ and a mean absolute error of $9.6 \%$. 


\section{Air mass observer}

Extensive research has been carried out on in-cylinder air mass observation, especially for air-fuel ratio (AFR) control. For air mass flow observation in a Port Fuel Injection (PFI) SI engine, Hendricks et al. (1992) and Chang et al. (1993) use an Extended Kalman Filter and Corde et al. (1995) use a flow Luenberger observer. Chevalier et al. (2000) predict the port air mass flow of SI engines in AFR control, with experimental results. Hendricks (2001) compares adiabatic and isothermal mean value engine models, and shows that for SI engines with Exhaust Gas Recirculation (EGR), adiabatic models are necessary. Hendricks and Luther (2001) make a critical review of existing air mass observers. Stotsky and Kolmanovsky (2002) use an "input observer" to determine the engine cylinder flow, which is extended in Stotsky et al. (2004) with a composite adaptation. Finally, Andersson and Eriksson (2004) use a Kalman filter to reconstruct the air mass for a turbocharged SI engine.

A novel observer for the in-cylinder air mass $m_{\text {air }}$ is presented below. Unlike the preceding references, it takes into account a non-measured phenomenon (scavenging), and can thus be applied with advanced engine technology (turbocharged VCT engine). Moreover, its on-line computational load is low. As presented in Fig. 5, this observer combines open loop non-linear static

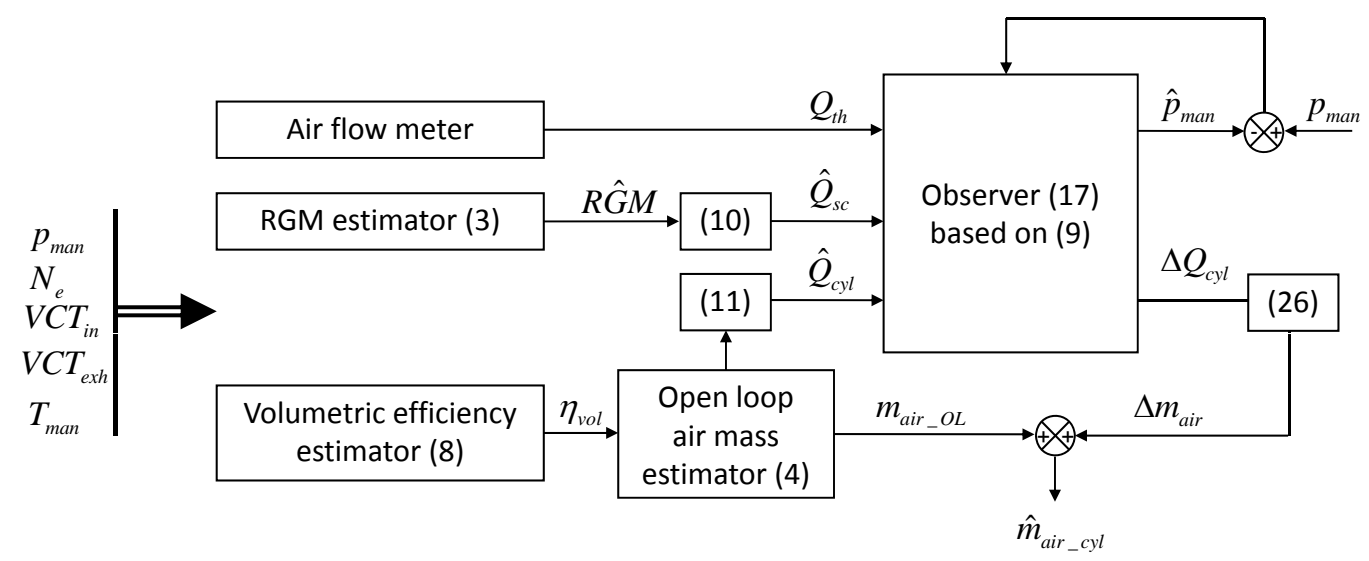

Figure 5: Air mass observer scheme

estimators of $R G M$ (section 2) and $m_{\text {air_OL }}$ (section 3.1), and a closed loop dynamic polytopic observer, described in section 3.2 , which dynamically com- 
pensates for the residual error $\Delta Q_{c y l}$ committed by one of the estimators, with a principle close to (Andersson, 2002).

\subsection{Open loop air mass estimator}

The open loop (feedforward) model of the in-cylinder air mass $m_{\text {air_OL }}$ is based on the volumetric efficiency equation:

$$
m_{a i r_{-} O L}=\eta_{v o l} \frac{p_{a m b} V_{c y l}}{r T_{\text {man }}},
$$

where $T_{\text {man }}$ is the manifold temperature, $p_{a m b}$ the ambient pressure, $V_{c y l}$ the displacement volume, $r$ the ideal gas constant, and where the volumetric efficiency $\eta_{v o l}$ is described by the static non-linear function $f$ :

$$
\eta_{v o l}=f\left(p_{\text {man }}, N_{e}, V C T_{i n}, V C T_{e x h}\right)
$$

The rest of this subsection is devoted to the approximation of the volumetric efficiency (5) by polynomial or neural models, and to the choice of the model finally selected. In (De Nicolao et al., 1996), various black box models, such as polynomial, spline, MLP and RBFN models, are compared for the static prediction of the volumetric efficiency.

Polynomial model linear in manifold pressure. Jankovic and Magner (2002) proposed the model, linear in manifold pressure, where $f_{1}$ and $f_{2}$ are $4^{\text {th }}$ order polynomials:

$$
\eta_{v o l}=f_{1}\left(N_{e}, V C T_{i n}, V C T_{e x h}\right) p_{m a n}+f_{2}\left(N_{e}, V C T_{i n}, V C T_{e x h}\right) .
$$

This model involves 69 parameters, but this number can be reduced to 43 by stepwise regression (Draper and Smith, 1998).

Polynomial model. The volumetric efficiency can be also represented by a $4^{\text {th }}$ order polynomial model:

$$
\eta_{v o l}=f_{3}\left(p_{\text {man }}, N_{e}, V C T_{i n}, V C T_{e x h}\right)
$$

The complete model involves 70 parameters, and the reduced model obtained by stepwise regression 58 parameters. 
Neural model. The volumetric efficiency (5) estimated by a neural model (2) is written as:

$$
\eta_{v o l}=f_{n n}\left(p_{m a n}, N_{e}, V C T_{i n}, V C T_{e x h}\right)
$$

As in section 2, training was performed by minimizing the mean squared error, with the Levenberg-Marquardt algorithm. Moreover, the Bayesian Information Criterion (BIC) and the Final Prediction Error (FPE) criterion are examined from the validation data when varying the number $n$ of hidden neurons. The optimal number, 6, corresponds to the minimum of the criteria as shown in Fig. 6, giving 37 parameters for the neural model. For

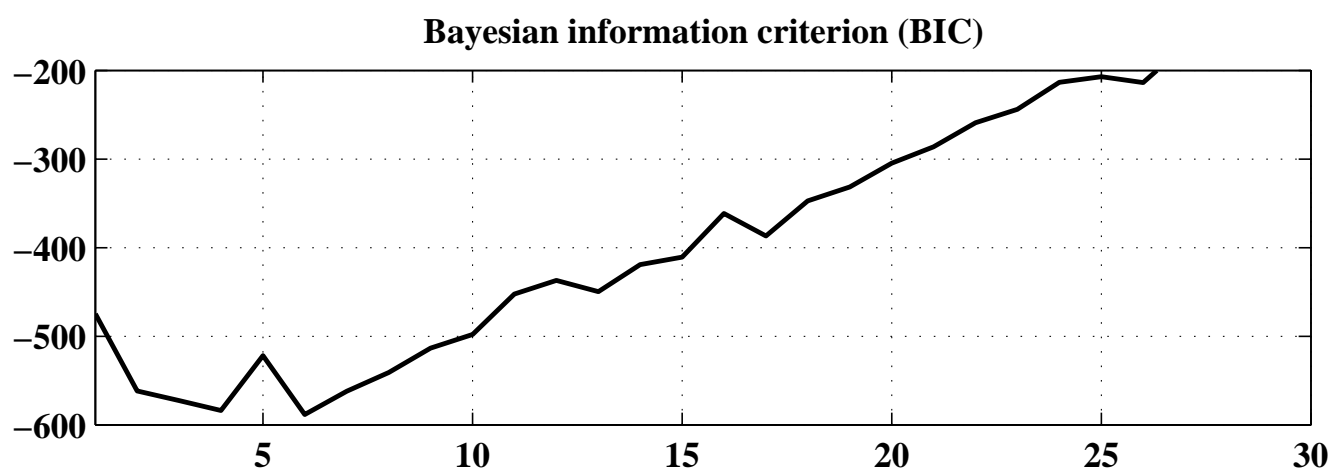

Final prediction error criterion (FPE)

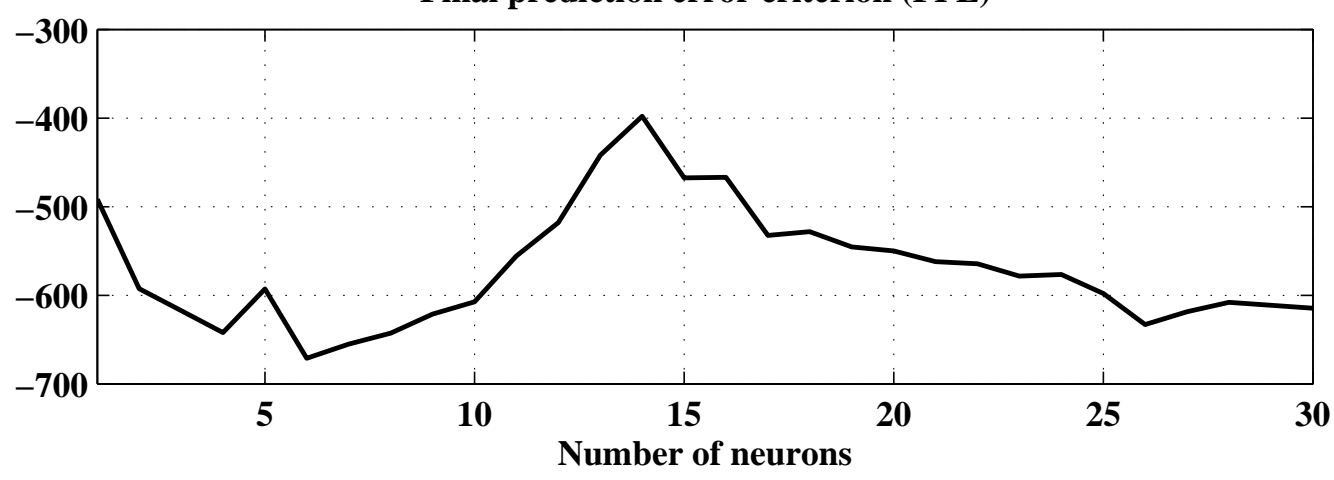

Figure 6: Bayesian Information Criterion (BIC, up) and Final Prediction Error criterion (FPE, down) w.r.t. the number of hidden neurons on the validation data for the volumetric efficiency neural model

validation data, the mean absolute error for $m_{\text {air_OL }}$ is $2.3 \%$. The maximum absolute errors (12 mg, $12 \%$ ) are obtained at low load and low engine speed 
$\left(N_{e}=700 \mathrm{rpm}\right.$ and $\left.p_{\operatorname{man}}=25 \mathrm{kPa}\right)$, where the physical phenomenon is the most non-linear. For test data, the estimator (8) makes larger errors than for the validation data, as shown in Fig. 7. On this figure, where the air mass is
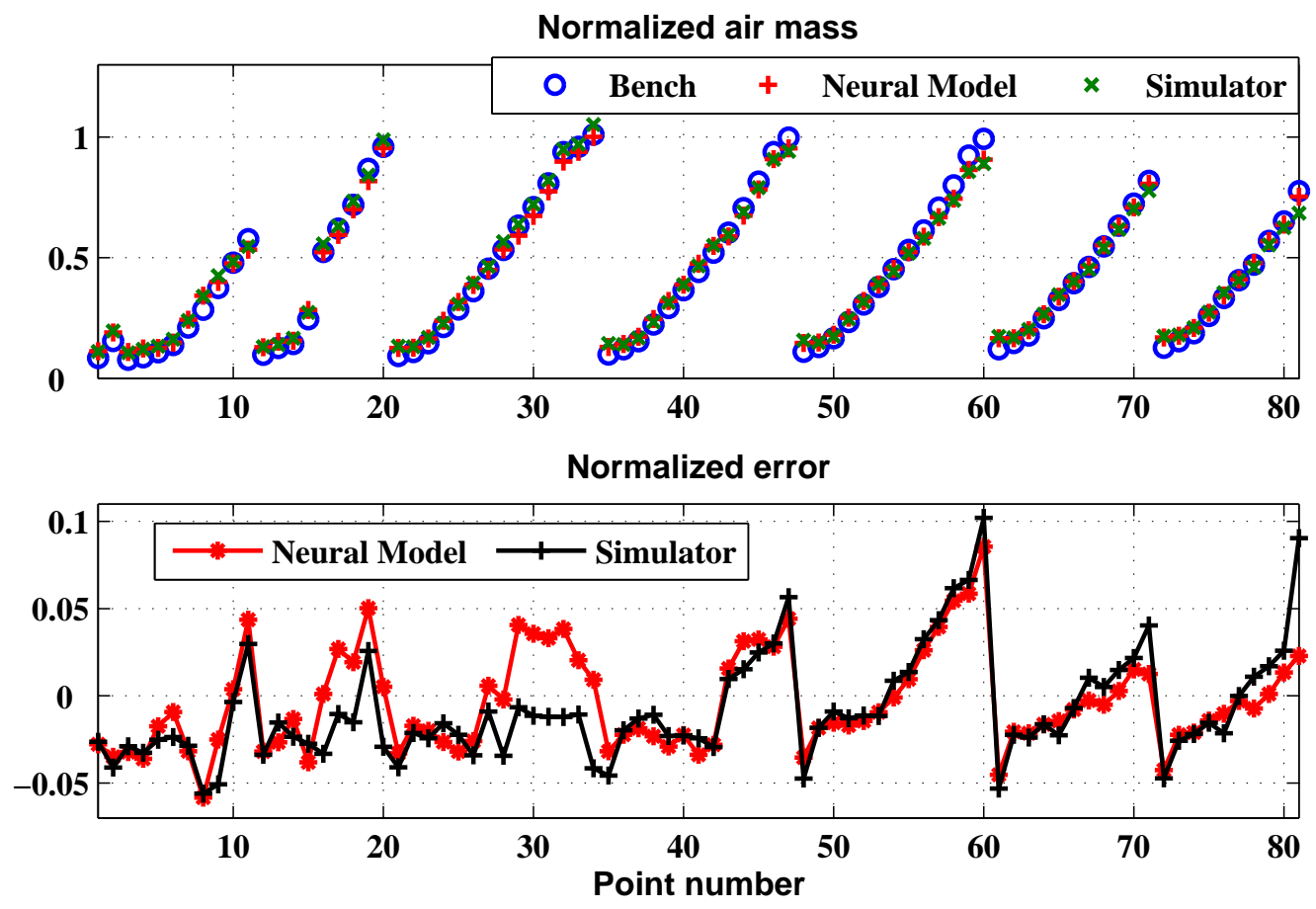

Figure 7: Air mass comparison between neural model, simulator and test bench data for static operating points: air mass (up, in $\mathrm{mg}$ ) and its error (down, in $\mathrm{mg}$ )

normalized between 0 and 1, the neural model errors mainly follow the simulator errors, because the neural model has been trained on the simulation data.

Comparison of the models. Table 1 compares the Root Mean Squared Error (RMSE) for $m_{\text {air_OL }}$ of the presented models: the polynomial model linear in manifold pressure (6) proposed by Jankovic and Magner (2002), complete with 69 parameters, then reduced to 43 parameters; the polynomial model (7), complete with 70 parameters then reduced to 58 parameters; the neural model (8) with 6 hidden neurons and 37 parameters. The behavior of these models is similar, and the most important errors are committed at the same operating points. In the following, the neural model, involving fewer 
Table 1: Static models comparison: RMSE for $m_{\text {air_oL }}(\mathrm{mg})$

\begin{tabular}{|l||c|c|c|c|}
\hline Models & $\begin{array}{c}\text { Test } \\
\text { (bench) }\end{array}$ & $\begin{array}{c}\text { Valid. } \\
\text { (simu. })\end{array}$ & $\begin{array}{c}\text { Learning } \\
\text { (simu.) }\end{array}$ & \# coef. \\
\hline \hline $\begin{array}{l}\text { Jankovic } \\
\text { (complete) }\end{array}$ & 30.67 & 15.66 & 15.73 & 69 \\
\hline $\begin{array}{l}\text { Jankovic } \\
\text { (reduced) }\end{array}$ & 30.84 & 15.49 & 15.86 & 43 \\
\hline $\begin{array}{l}\text { Polynomial } \\
\text { (complete) }\end{array}$ & 28.87 & 9.88 & 9.6 & 70 \\
\hline $\begin{array}{l}\text { Polynomial } \\
\text { (reduced) }\end{array}$ & 28.79 & 9.92 & 9.61 & 58 \\
\hline $\begin{array}{l}\text { Neural } \\
\text { model }\end{array}$ & 28.49 & 9.36 & 10.39 & 37 \\
\hline
\end{tabular}

parameters and yielding the smallest RMSE for validation and test data, is chosen as the static model of the volumetric efficiency. The results illustrate the parsimony of neural models.

\subsection{Air mass observer}

\subsubsection{Principle}

The air mass observer is based on the flow balance in the intake manifold. As shown in Fig. 8, a flow $Q_{t h}$ enters the manifold and two flows leave it: the flow that is captured in the cylinder $Q_{c y l}$ and the flow scavenged from the intake to the exhaust $Q_{s c}$. As introduced in Fig. 5, the flow balance in the manifold can thus be written:

$$
\dot{p}_{\text {man }}(t)=\frac{r T_{\text {man }}(t)}{V_{\text {man }}}\left(Q_{t h}(t)-Q_{c y l}(t)-\Delta Q_{c y l}(t)-Q_{s c}(t)\right),
$$

where, for the intake manifold, $p_{\text {man }}$ is the pressure to be estimated (in Pa), $T_{\text {man }}$ the temperature $(\mathrm{K}), V_{\text {man }}$ the volume $\left(\mathrm{m}^{3}\right)$, assumed to be constant, and $r$ is the ideal gas constant. $Q_{t h}(t)$ is measured by an air flow meter $(\mathrm{kg} / \mathrm{s}) . \quad Q_{s c}(t)(\mathrm{kg} / \mathrm{s})$ can be obtained by differentiating the Recirculated Gas Mass $\widehat{R G M}(3)$ :

$$
\hat{Q}_{s c}(t)=\min (-\widehat{R G M}(t), 0) / t_{t d c}(t),
$$




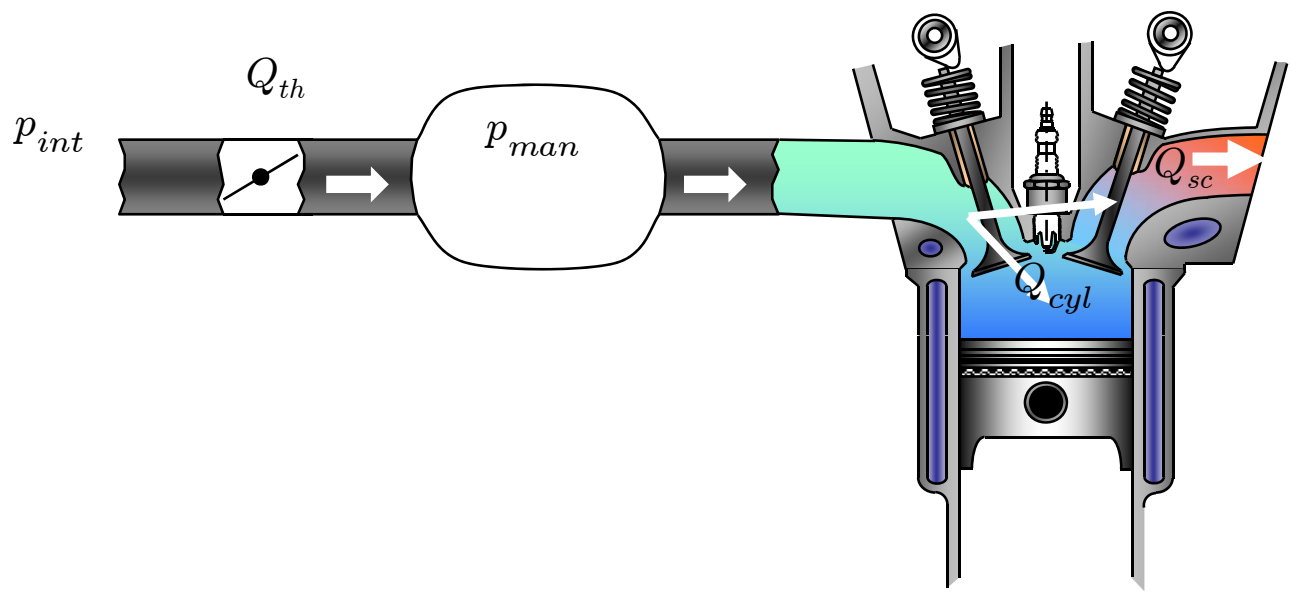

Figure 8: Separation of the fresh air flows from the manifold

where $t_{t d c}(t)=\frac{2 \times 60}{N_{e}(t) n_{c y l}}$, with the engine speed $N_{e}$ (rpm) and the number of cylinders $n_{c y l}$, is the variable sampling period between two intake Top Dead Centers (TDC). $Q_{c y l}(t)(\mathrm{kg} / \mathrm{s})$ is determined from the open loop model of the in-cylinder air mass (4) with the neural model (8):

$$
\hat{Q}_{c y l}(t)=m_{\text {air_oL }}(t) / t_{t d c}(t)
$$

Finally, in (9), $\Delta Q_{c y l}(t)$ is the error made by the model (11), which has to be dynamically compensated.

To this end, considering slow variations of $\Delta Q_{c y l}(t)$, i.e. $\dot{\Delta} Q_{c y l}(t)=0$, the following state space representation can be written:

$$
\left\{\begin{array}{l}
\dot{X}(t)=A X(t)+B U(t) \\
y(t)=C X(t)
\end{array}\right.
$$

with:

$$
X(t)=\left(\begin{array}{c}
p_{\operatorname{man}}(t) \\
\Delta Q_{c y l}(t)
\end{array}\right), \quad U(t)=\left(\begin{array}{c}
Q_{t h}(t) \\
Q_{c y l}(t) \\
Q_{s c}(t)
\end{array}\right), \quad y(t)=p_{\text {man }}(t),
$$

and, noting $a(t)=-\frac{r T_{\operatorname{man}}(t)}{V_{\operatorname{man}}}$, with:

$$
A=\left(\begin{array}{cc}
0 & a(t) \\
0 & 0
\end{array}\right), \quad B=\left(\begin{array}{ccc}
-a(t) & a(t) & a(t) \\
0 & 0 & 0
\end{array}\right), \quad C=\left(\begin{array}{ll}
1 & 0
\end{array}\right) .
$$


Note that system (12), with (14), is Linear Parameter Varying (LPV), because the matrices $A$ and $B$ depend linearly on the (measured) parameter $a(t)$. Next, this system is discretized at each top dead center (TDC) to give:

$$
\left\{\begin{array}{l}
X_{k+1}=A_{d} X_{k}+B_{d} U_{k} \\
y_{k}=C X_{k}
\end{array}\right.
$$

where:

$$
A_{d}=t_{t d c} A+I=\left(\begin{array}{cc}
1 & \rho_{k} \\
0 & 1
\end{array}\right), B_{d}=t_{t d c} B=\left(\begin{array}{ccc}
-\rho_{k} & \rho_{k} & \rho_{k} \\
0 & 0 & 0
\end{array}\right)
$$

with $\rho_{k}=-\frac{r T_{\operatorname{man}}(k)}{V_{\operatorname{man}}} t_{t d c}(k)$, where $t_{t d c}(k)=\frac{2 \times 60}{N_{e}(k) n_{c y l}}$ is the variable sampling period between two intake TDC. In turn, $\rho_{k}$ is a time varying parameter, which depends now on the manifold temperature $T_{\text {man }}(k)$ and engine speed $N_{e}(k)$, and the discrete time system (15), with $A_{d}=A_{d}\left(\rho_{k}\right)$, is still a LPV system.

The state reconstruction for system (15) can be achieved by resorting to a so-called polytopic observer with a constant gain $K$, of the form:

$$
\left\{\begin{array}{l}
\hat{X}_{k+1}=A_{d}\left(\rho_{k}\right) \hat{X}_{k}+B_{d}\left(\rho_{k}\right) U_{k}+K\left(y_{k}-\hat{y}_{k}\right) \\
\hat{y}_{k}=C \hat{X}_{k}
\end{array}\right.
$$

Some details on the design of polytopic observers, for the general case where the time varying parameter $\rho_{k}$ is a vector, are presented below. If $\rho_{k}$ is bounded, it evolves in a compact set and thereby can always be included in a convex polytope $\mathcal{D}_{\rho}$. Hence, $\rho_{k}$ admits a polytopic decomposition, expressed as:

$$
\rho_{k}=\sum_{i=1}^{N} \xi_{k}^{(i)} \theta_{i}
$$

where the vector $\xi_{k}$ belongs to the convex set $S=\left\{\mu_{k} \in \mathbb{R}^{N}, \mu_{k}=\left[\mu_{k}^{(1)} \ldots \mu_{k}^{(N)}\right]^{T}\right.$, $\left.\mu_{k}^{(i)} \geq 0 \quad \forall i, \sum_{i=1}^{N} \mu_{k}^{(i)}=1\right\}$. The constant vectors $\theta_{i}, \ldots, \theta_{N}$ are the $N$ vertices of the convex polytope $\mathcal{D}_{\rho}$. Since $A_{d}$ depends linearly on $\rho_{k}$, it is shown in (Millérioux et al., 2005) that $A_{d}\left(\rho_{k}\right)$ can always be decomposed in a polytopic form as:

$$
A_{d}\left(\rho_{k}\right)=\sum_{i=1}^{N} \xi_{k}^{(i)} \mathcal{A}_{d}^{(i)}
$$


The vector $\xi_{k}$ coincides with the one involved in (18). The constant matrices $\mathcal{A}_{d}^{(1)}, \ldots, \mathcal{A}_{d}^{(N)}$ are the $N$ vertices of the convex polytope $\mathcal{D}_{A_{d}}$ including the compact set where $A_{d}\left(\rho_{k}\right)$ evolves.

The state reconstruction error $\epsilon_{k}=X_{k}-\hat{X}_{k}$, obtained from (15), (17) and (19), is thus governed by:

$$
\epsilon_{k+1}=\left(A_{d}\left(\rho_{k}\right)-K C\right) \epsilon_{k}=\sum_{i=1}^{N} \xi_{k}^{(i)}\left(\mathcal{A}_{d}^{(i)}-K C\right) \epsilon_{k}
$$

The dynamics of the state reconstruction is time-varying since $A_{d}$ depends on $\rho_{k}$. Thus, (20) is an LPV system. The conditions of global convergence toward zero of the state reconstruction are ensured from the following theorem (Millérioux et al., 2004).

Theorem 1. Global convergence of (20) is achieved whenever the following set of Linear Matrix Inequalities

$$
\left[\begin{array}{cc}
P_{i} & \mathcal{A}_{d}^{(i) T} G^{T}-C^{T} F^{T} \\
G \mathcal{A}_{d}^{(i)}-F C & G+G^{T}-P_{j}
\end{array}\right]>0
$$

is feasible for all $(i, j) \in\{1, \ldots, N\} \times\{1, \ldots, N\}$.

Matrix $G$, matrix $F$ and matrices $P_{i}$ 's are unknown. The gain $K$ is given by:

$$
K=G^{-1} F
$$

It can be shown that (21) ensures the existence of a so-called poly-quadratic Lyapunov function $V: \mathbb{R}^{n} \rightarrow \mathbb{R}^{+}$, defined by $V\left(\epsilon_{k}\right)=\epsilon_{k}^{T} \mathcal{P}_{k} \epsilon_{k}$, with $\mathcal{P}_{k}=$ $\sum_{i=1}^{N} \xi_{k}^{(i)} P_{i}, \xi_{k} \in S$, fulfilling

$$
V\left(\epsilon_{k+1}\right)-V\left(\epsilon_{k}\right)<0 .
$$

The existence of such a Lyapunov function guarantees the polyquadratic stability of the state reconstruction error (Daafouz and Bernussou, 2001).

In the case of system (15), the time varying parameter $\rho_{k}$ is scalar, and the polytopic decomposition reduces to elementary computations. Indeed, $\rho_{k}$ evolves between a minimum value $\rho_{\min }$ and a maximum value $\rho_{\max }$. The convex polytope $\mathcal{D}_{\rho}$ has $N=2$ vertices, $\theta^{(1)}=\rho_{\min }$ and $\theta^{(2)}=\rho_{\max }$. Thus, 
(18) turns into $\rho_{k}=\xi_{k}^{(1)} \rho_{\text {min }}+\xi_{k}^{(2)} \rho_{\text {max }}$. Since $\sum_{i=1}^{N} \xi_{k}^{(i)}=1, \rho_{k}=\xi_{k}^{(1)} \rho_{\text {min }}+$ $\left(1-\xi_{k}^{(1)}\right) \rho_{\max }$. And (19) is reduced to:

$$
A_{d}\left(\rho_{k}\right)=\xi_{k}^{(1)} \mathcal{A}_{d}^{(1)}+\left(1-\xi_{k}^{(1)}\right) \mathcal{A}_{d}^{(2)}
$$

with:

$$
\mathcal{A}_{d}^{(1)}=\left(\begin{array}{cc}
1 & \rho_{\min } \\
0 & 1
\end{array}\right), \quad \mathcal{A}_{d}^{(2)}=\left(\begin{array}{cc}
1 & \rho_{\max } \\
0 & 1
\end{array}\right) .
$$

$\rho_{\min }=-401.44$ corresponds to an engine speed of $N_{e}=50 \mathrm{rpm}$ and a manifold temperature of $T_{\text {man }}=373 \mathrm{~K}$, and $\rho_{\max }=-2.0897$ to $N_{e}=6000$ $\mathrm{rpm}$ and $T_{\text {man }}=233 \mathrm{~K}$. The software Yalmip, available free of charge at http://control.ee.ethz.ch/ joloef/yalmip.php, solves the LMI (21), with $N=2$ and the matrices $\mathcal{A}_{d}^{(1)}$ and $\mathcal{A}_{d}^{(2)}$ of (25). It turns out that these LMI are feasible. From the resulting matrices $G$ and $F$, the constant gain $K$ is computed by $(22)$, giving $K=(1.3217-0.0022)$.

The state $\Delta Q_{c y l}$ is then integrated (i.e. multiplied by $t_{t d c}$ ) to give the air mass bias $\Delta m_{\text {air }}$ :

$$
\Delta m_{\text {air }}=t_{t d c} \Delta Q_{c y l} .
$$

Finally, the in-cylinder air mass can be estimated by correcting the open loop estimator (4) with this bias:

$$
\hat{m}_{\text {air_cyl }}=m_{\text {air_oL }}+\Delta m_{\text {air }} .
$$

\subsubsection{Results}

Some experimental results obtained on the 1.8 liter turbocharged 4 cylinder engine with VCT are given in Fig. 9 and 10. Fig. 9 shows an example of the good dynamic reconstruction of the manifold pressure $p_{\text {man }}$ by the first state of the observer (17).

Fig. 10 illustrates the observer of the in-cylinder air mass, normalized between 0 and 1. A measurement of this mass, only valid in steady state, can be obtained by integrating, i.e. multiplying by $t_{t d c}$, the flow that passes through the throttle $Q_{t h}$. In steady state with no scavenging, the air flow that enters the cylinder $Q_{c y l}$ is equal to $Q_{t h}$ (see Fig. 8). Fig. 10 compares the following: this measurement; the open loop neural estimator: (4) with (8); an estimation not based on this neural model: observer (17) based on model (9) but with $Q_{c y l}=Q_{s c}=0$; the proposed estimation: (27) combining 


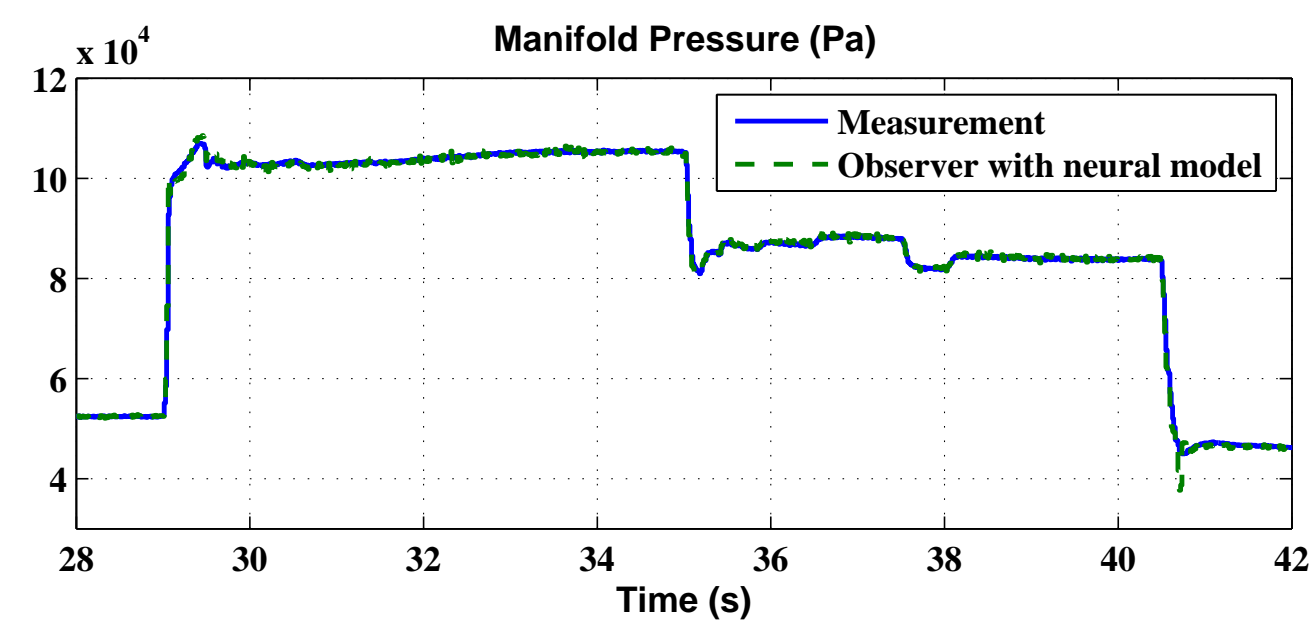

Manifold pressure estimation error $(\mathrm{Pa})$

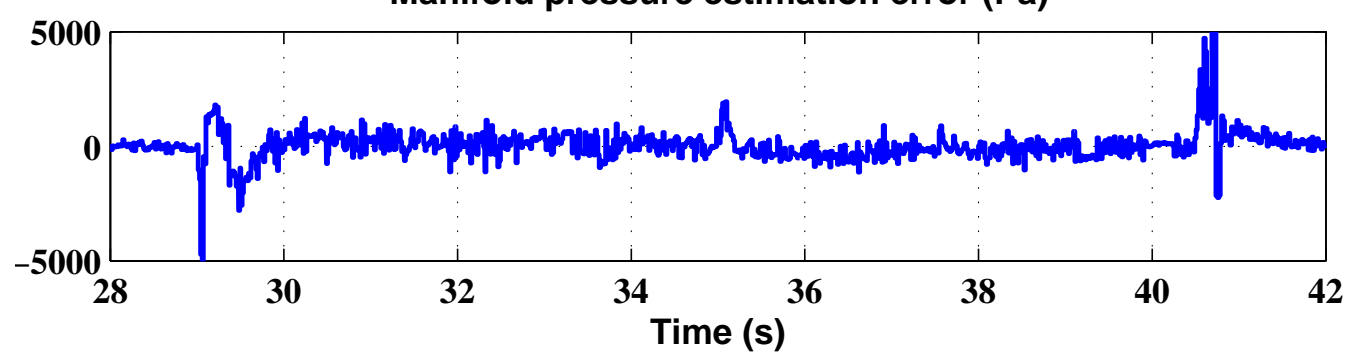

Figure 9: Manifold pressure measurement $p_{\text {man }}$ and estimation $\hat{p}_{\text {man }}$ (up, in Pa) and the estimation error (down, in $\mathrm{Pa}$ ) vs. time $(\mathrm{s})$ on the engine test bench

the open loop neural estimator (4), with (8) and the polytopic observer (17) based on model (9) with $Q_{c y l}$ given by (11) from (4), with (8), and $Q_{s c}$ given by (10) using (3). For steps of air flow, the open loop neural estimator tracks very quickly the measurement changes, but a small steady state error can be observed (see for example between $32 \mathrm{~s}$ and $34 \mathrm{~s}$ ). Conversely, the closed loop observer which does not take this feedforward estimator into account involves a long transient error while guaranteeing convergence in steady state. Finally, the proposed estimator including feedforward static estimators and polytopic observer combines both advantages: very fast tracking, and no steady state error. 


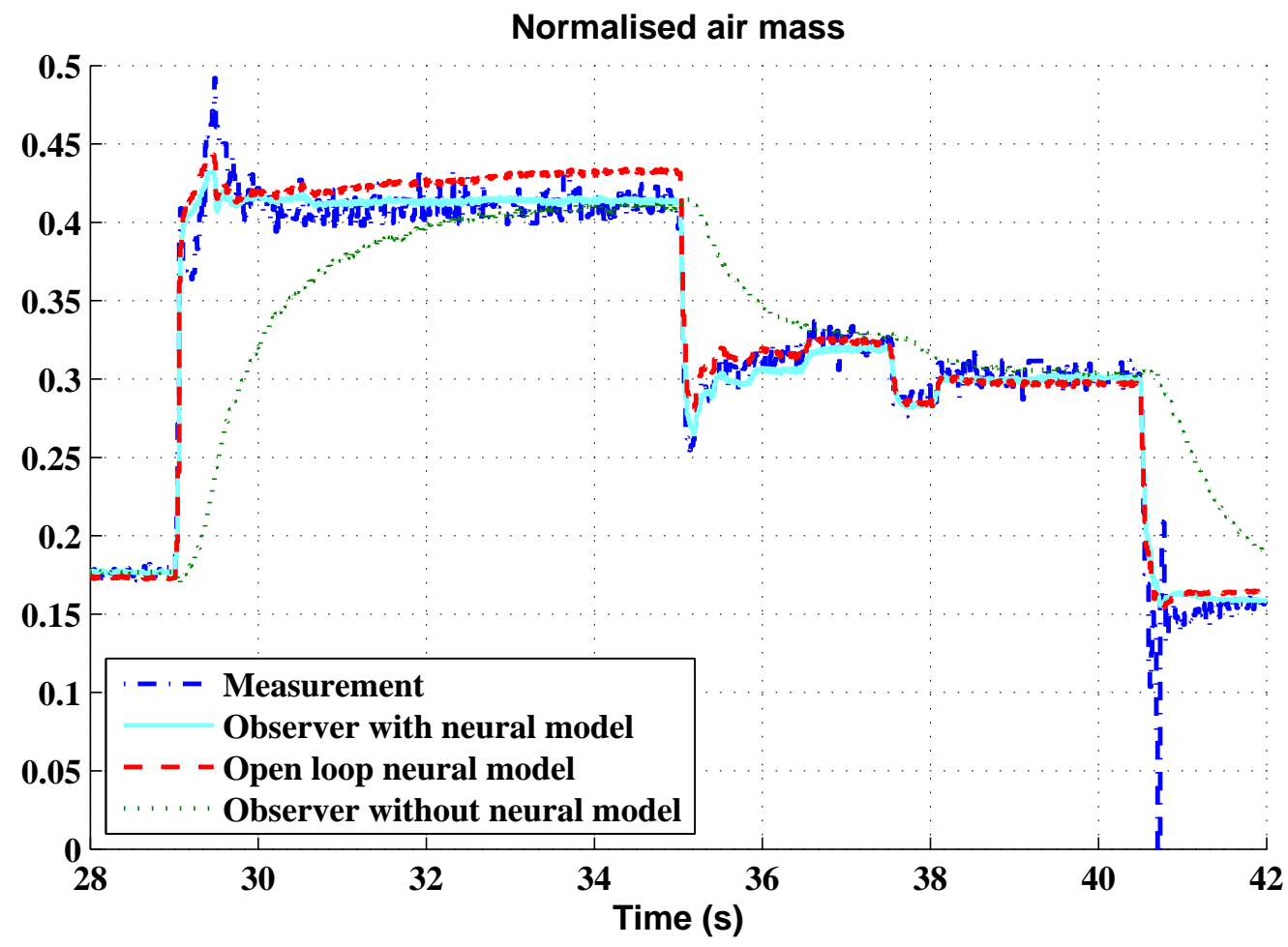

Figure 10: Air mass observer results vs. time (s) on the engine test bench: air mass obtained from the measurement of $Q_{t h}$ (blue dash dot), open loop neural estimator (red dash), observer without neural estimators (green dot), observer including neural models (light blue solid)

\section{Set point optimization}

The two non-linear estimators of the recirculated gas mass (section 2) and of the air mass trapped in the cylinder (section 3) have now been validated. The control scheme (Fig. 2) based on these estimators can control the incylinder air mass for different recirculated gas mass values (by manipulating the cam timing). Thus, tests can be performed in order to optimize the set points provided by the supervisor level to the control.

An example of preliminary static results obtained on the test bench is shown in Figs. 11 and 12. The test consists in increasing the residual burned gas fraction with a constant in-cylinder air mass and observing the pollutant emissions, fuel consumption, and exhaust temperature. The increase in the 
in-cylinder burned gas fraction (and thus in the manifold pressure) is achieved by acting on valve overlapping. This test was carried out at $1000 \mathrm{rpm}$ with a fixed Air-Fuel Ratio (1 at the lambda sensor, i.e. at stoechimetry).

In the figures, the operating point number 2 corresponding to $26.5 \%$ of

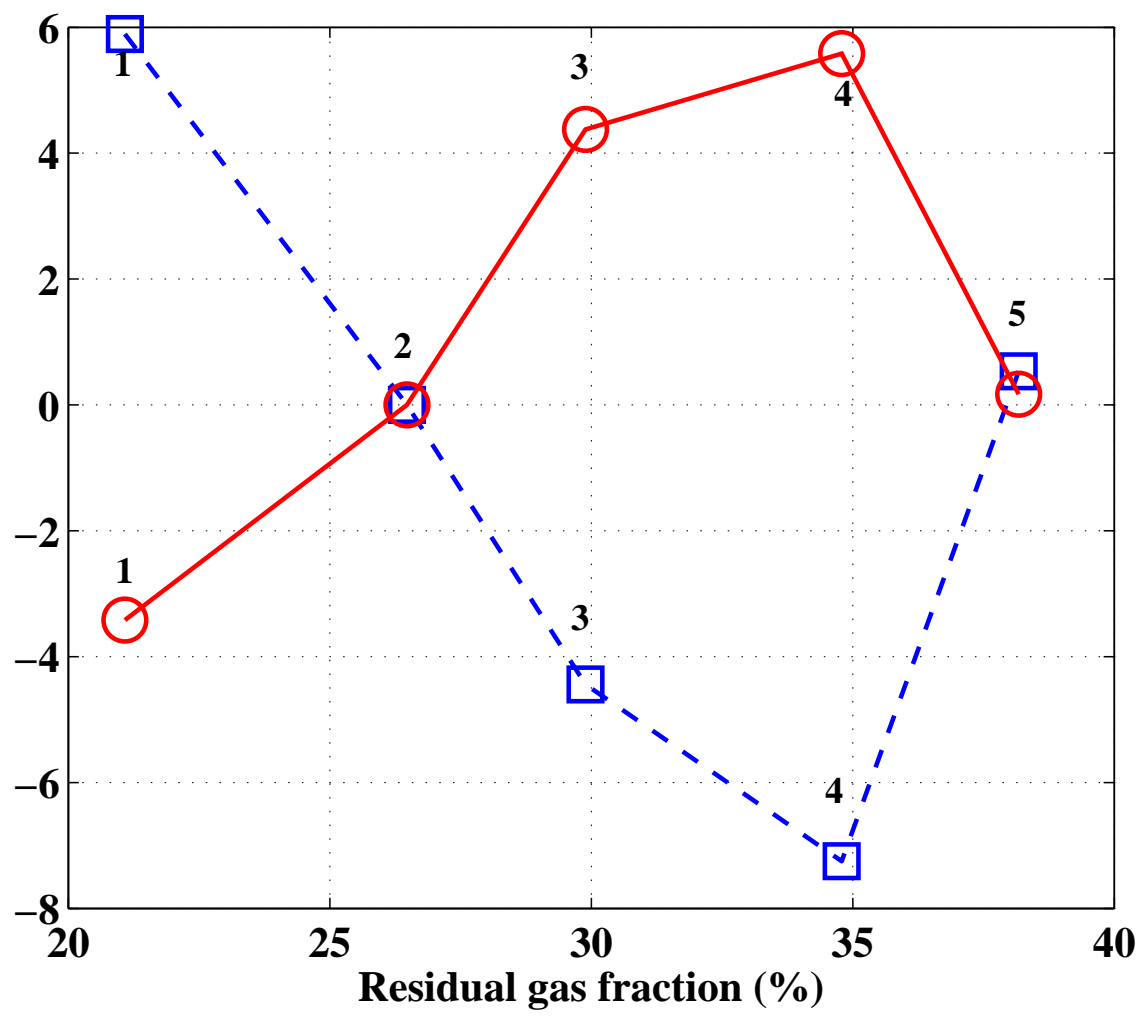

Figure 11: Variation of Brake Specific Fuel Consumption (BSFC, \%, blue dashed line) and Indicated Mean Effective Pressure (IMEP, \%, red solid line) w.r.t. residual gas fraction $(\%)$

residual gas rate was chosen initially by an engine bench operator as the best compromise. The operating point number 5 with $38 \%$ of residual gas rate involves unstable combustion and must be rejected. The point number 4 with $35 \%$ of residual gas rate is the one producing the maximum torque (IMEP), by reducing pumping losses, without unstable combustion (see Fig. 11). A margin on residual gases set point can be added for stable combustion. This point corresponds to minimum fuel consumption $(B S F C)$ (see Fig. 11) and 


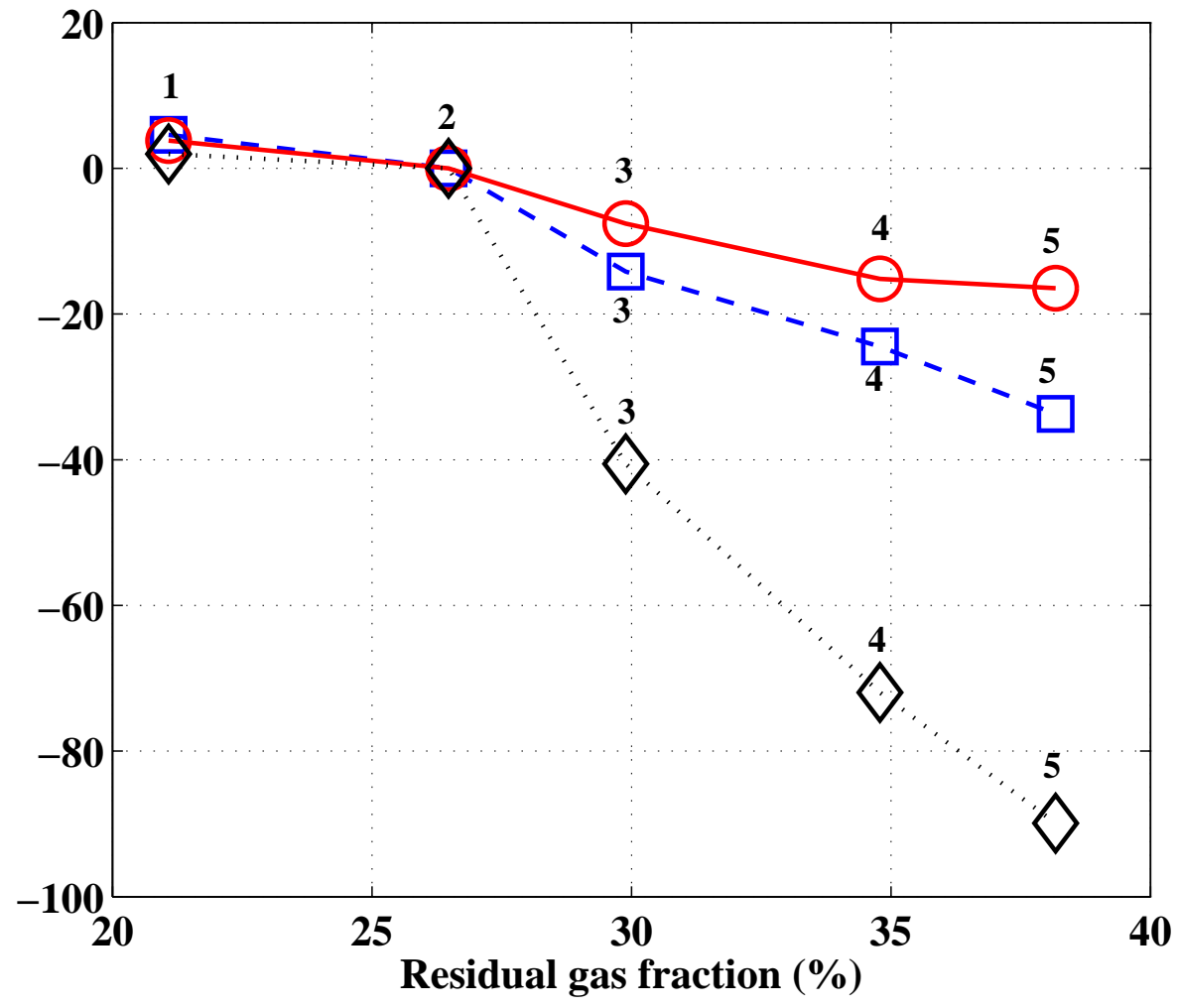

Figure 12: Pollutant emissions (\%) : $N O_{x}$ (black dash-dotted line), $H C$ (blue dashed line), $C O$ (red solid line) w.r.t. residual gas fraction (\%)

pollutant emissions $\left(\mathrm{NO}_{x}, \mathrm{CO}\right.$ and $\left.\mathrm{HC}\right)$ (see Fig. 12). Moreover, it involves a maximum exhaust temperature that is useful for catalyst heating. This point therefore seems to be the best option. That calls into question the initial choice of the point corresponding to $26.5 \%$ of residual gas rate given by a static map of the "reference" points.

\section{Conclusion}

The inclusion of neural models in several estimators for automotive engines has been presented. These neural models permit extending two-dimensional static maps by taking into account, for example, the variable valve timing for the volumetric efficiency. The intrinsic bias of the open loop model 
is corrected by a polytopic observer built from the Linear Parameter Varying model of the system. The proposed approach has been tested on a non-linear fast coupled system, the air intake control of a turbocharged SI engine with VCT, with the aim of downsizing. The proposed observers, included in the air actuators control scheme, permit to make tests with a constant in-cylinder air mass while increasing in-cylinder burned gases. These static tests show that new possibilities are offered in order to decrease pollutant emissions and optimize engine efficiency. Further research will thus deal with the complete supervisor synthesis.

\section{Acknowledgment}

The authors are grateful to F. Le Berr for calibrating the simulator and G. Le Solliec for integrating the observers on the engine test bench.

\section{References}

Andersson, P., 2002. Intake Air Dynamics on a Turbocharged SI-Engine with Wastegate. Ph.D. thesis, Linköping University, Sweden.

Andersson, P., Eriksson, L., April 2004. Mean-Value Observer for a Turbocharged SI-Engine. In: IFAC Symposium on Advances in Automotive Control. Salerno, Italy, pp. 146-151.

Chang, C., Fekete, N., Powell, J., 1993. Engine Air-Fuel Ratio Control Using an Event-Based Observer. SAE Technical Paper, n 930766.

Chevalier, A., Vigild, C., Hendricks, E., 2000. Predicting the Port Air Mass Flow of SI Engines in Air/Fuel Ratio Control Applications. SAE Technical Paper, n²000-01-0260.

Colin, G., Chamaillard, Y., Bloch, G., Corde, G., July 2007. Neural Control of Fast Nonlinear Systems - Application to a Turbocharged SI Engine with VCT. IEEE Trans. on Neural Networks 18 (4), 1101-1114.

Corde, G., Bianco, Y., Lecluse, Y., 1995. Air mass flow rate observer applied to SI AFR control. SAE Technical Paper, n 952460.

Daafouz, J., Bernussou, J., August 2001. Parameter dependent Lyapunov functions for discrete time systems with time varying parametric uncertainties. Systems \& Control Letters 43 (5), 355-359. 
De Nicolao, G., Scattolini, R., Siviero, C., 1996. Modelling the volumetric efficiency of IC engines: parametric, non-parametric and neural techniques. Control Engineering Practice 4 (10), 1405-1415.

Draper, N., Smith, H., 1998. Applied Regression Analysis, 3rd Edition. John Wiley.

Frei, S. A., Guzzella, L., Onder, C. H., Nizzola, C., 2006. Improved dynamic performance of turbocharged SI engine power trains using clutch actuation. Control Engineering Practice 14 (4), 363-373.

Hendricks, E., March 2001. Isothermal vs. Adiabatic Mean Value SI Engine Models. In: 3rd IFAC Workshop on Advances in Automotive Control. Karlsruhe, Germany, pp. 373-378.

Hendricks, E., Luther, J., 2001. Model and observer based control of internal combustion engines. In: Modeling, Emissions and Control in Automotive Engines (MECA). Salerno, Italy.

Hendricks, E., Vesterholm, T., Sorenson, S., 1992. Nonlinear, Closed Loop, SI Engine Control Observers. SAE Technical Paper, nº 920237.

Jankovic, M., Magner, S., 2002. Variable Cam Timing : Consequences to Automotive Engine Control Design. In: 15th Triennial IFAC World Congress. Barcelona, Spain.

Le Berr, F., Miche, M., Colin, G., Solliec, G. L., Lafossas, F., 2006. Modelling of a Turbocharged SI Engine with Variable Camshaft Timing for Engine Control Purposes. SAE Technical Paper, n²006-01-3264.

Lecointe, B., Monnier, G., 2003. Downsizing a Gasoline Engine Using Turbocharging with Direct Injection. SAE Technical Paper, n²003-01-0542.

Millérioux, G., Anstett, F., Bloch, G., February 2005. Considering the attractor structure of chaotic maps for observer-based synchronization problems. Mathematics and Computers in Simulation 68 (1), 67-85.

Millérioux, G., Rosier, L., Bloch, G., Daafouz, J., August 2004. Bounded state reconstruction error for LPV systems with estimated parameters. IEEE Trans. on Automatic Control 49 (8), 1385-1389. 
Nelles, O., 2000. Nonlinear System Identification. Springer.

Stotsky, A., Kolmanovsky, I., 2002. Application of input estimation techniques to charge estimation and control in automotive engines. Control Engineering Practice 10 (12), 1371-1383.

Stotsky, A., Kolmanovsky, I., Eriksson, S., 2004. Composite adaptive and input observer-based approches to the cylinder flow estimation in spark ignition automotive engines. International Journal of Adaptive Control and Signal Processing 18 (2), 125-144. 